\title{
Montmorillonite Nanoparticles Effectiveness in Removal of Amoxicillin from Water Solutions
}

\author{
Davoud Balarak', Fatemeh Ganji², Kethineni Chandrika³ ${ }^{3}$ Shaziya Haseeb4* \\ 'Department of Environmental Health, Health Promotion Research Center, Zahedan University of Medical Sciences, Zahedan, IRAN. \\ 2Department of Environmental Health- Student Research Committee, Zahedan University of Medical Sciences, Zahedan, IRAN. \\ 3Department of Biotechnology, Koneru Lakshmaiah Education Foundation, Vaddeswaram, Guntur, Andhra Pradesh, INDIA. \\ ${ }^{4}$ Environmental Research Laboratory, Department of Applied Chemistry, Aligarh Muslim University, Aligarh, Uttar Pradesh, INDIA.
}

\begin{abstract}
Objectives: In this article, novel montmorillonite nanoparticles (MON-NP) evaluated in order to facilitatethe sorption of Amoxicillin (AMO) from aqueous solutions in batch operations. Methods: Batch experiments were performed to study the influence of various experimental parameters such as contact time, adsorbent dosage, initial concentration of the AMO and temperatures at fixed solution $\mathrm{pH}$. The Langmuir, Freundlich and DubninRandkovich (D-R) models were subjected to sorption data to estimate sorption capacity, intensity and energy. Results: The optimum conditions of sorption were found as follows: a sorbent amountof $0.8 \mathrm{~g}$ in $\mathrm{L}$ of AMO solution (10 mg/L), contact time $90 \mathrm{~min}$ atfixed $\mathrm{pH}$ and temperature 7 and $25^{\circ} \mathrm{C}$, respectively. To study the kinetics of removal process, three equations, i.e. Morris-Weber, Lagergren (pseudo first order) and pseudo second order were used. The AMO sorption process waswell described by the
\end{abstract}

pseudo second order kinetic model. The maximum adsorption capacity (qe) from Langmuir isotherm model was determined to be $39.41 \mathrm{mg} / \mathrm{g}$ and for D-R isotherm was 32.47. Conclusion: The results indicate that MON-NP could be employed as a low-cost in wastewater treatment for the removal of AMO.

Key words: Montmorillonite, Nanoparticles, Amoxicillin, Isotherm, Kinetic.

Correspondence

\section{Dr. Shaziya Haseeb}

Environmental Research Laboratory, Department of Applied Chemistry, Aligarh Muslim University, Aligarh-202002, Uttar Pradesh, INDIA.

Email: mbehdasht75@gmail.com

DOI: 10.5530/ijpi.2020.2.22

\section{INTRODUCTION}

With the widespread use of antibiotics, pharmaceutical effluents containing antibiotics have recently attracted wide attentions since it has potential adverse effects. ${ }^{1,2}$ Although the injuriousness of antibiotics is not so intuitive like other environmental pollution, residues of the antibiotic drug have become a seriously ignoredproblem. ${ }^{3,4}$ The abuse of antibiotics can damage the immune functionof animals, when again infected and then they need more antibiotics to treat. Thus, it could sink into a vicious cycle.,

In recent years, the adsorption process has been considered for removal of many elements. ${ }^{7}$ The operation of adsorption process is dependent on many parameters such as $\mathrm{pH}$, the kind of adsorbent and the kind of pollutant. ${ }^{8,9}$ For this purpose, many adsorbents for removal of antibiotics have been used such as activated carbon, brick powder, activated alumina and charcoal. ${ }^{10,11}$ Activated carbon has been widely used for this purpose because of its high adsorption capacity. However, its high cost sometimes tends to limit its use. ${ }^{12,13}$

Clays are widely applied in many fields such as polymer nano-composites, adsorbent, catalysts, photochemical reaction fields, ceramics, paper filling and coating, sensors and biosensors, due to their high specific surface area, chemical and mechanical stabilities and a variety of surface and structural properties. ${ }^{14,15}$ The most-used clays as nano-adsorbents are montmorillonite/smectite group and kaolinite group clays. ${ }^{16,17}$

This paper reports on the ability of montmorillonite clay (MC) to remove AMO from aqueous solution. ${ }^{18}$ Clay has already been shown to have a high adsorption capacity, which may even exceed that of activated carbon under the same conditions of temperature and $\mathrm{pH} .{ }^{19}$
For the present study, a batch-contact-time method was used and the equilibrium of AMO adsorption on to MON-NP was investigated with attempts to fit the data to Langmuir, Freundlich and DubininRadushkevich (D-R) equations. The uptake of AMO on MON-NP was examined as a function of adsorbate concentration, adsorbent concentration and contact time.

\section{MATERIALS AND METHODS}

Amoxicillin (CAS Number 26787-78-0; chemical formula, $\mathrm{C}_{16} \mathrm{H}_{19} \mathrm{~N}_{3} \mathrm{O}_{4} \mathrm{~S}$; MW, $365.40 \mathrm{~g} / \mathrm{mol}$ ) was used as the adsorbent in this study obtained from Sigma Aldrich Co; it was used without further purification. A Montmorillonite nanoparticle was obtained from the Iranian Nanosany Corporation and was used without further purification.

The $1000 \mathrm{mg} / \mathrm{L}$ stock solution of AMO was prepared by dissolving 1 $\mathrm{g}$ of AMO powder in one liter of distilled water. In the present study, Laboratory Erlenmeyerflasks were used for adsorption experiments. Batch sorption experiments were performed at a constant temperature of $25^{\circ} \mathrm{C}$ on a magnetic mixer at $150 \mathrm{rpm}$. Through the dilution of $1 \mathrm{~g} / \mathrm{L}$ stock solutions, $100 \mathrm{~mL}$ of the AMO solution was prepared for each adsorption test. Using the diluted solution of hydrochloric acid or sodium hydroxide, the initial $\mathrm{pH}$ was adjusted to variable values. Also different concentrations of $\operatorname{AMO}(10,25,50,100 \mathrm{mg} / \mathrm{L})$ at various dosage of nano adsorbent $(0.1,0.2,0.4,0.6,0.8$ and $1 \mathrm{~g} / \mathrm{L})$ at different reaction times were studied for the optimization of the AMO removal process with MON-NP. After that, the solutions were filtered through a $0.45 \mu \mathrm{m}$ filter and finally AMO concentrations were measured with a spectrophotometer (HACH DR 5000) at $280 \mathrm{~nm}$ wavelength. The 
adsorption capacity of MON-NP in the removal of AMO was calculated using the following equation: ${ }^{20,21}$

$$
\mathrm{q}_{\mathrm{e}}=\frac{(\text { Co-Ce }) \times \mathrm{V}}{\mathrm{M}}
$$

Where $\mathrm{C}_{0}$ is initial concentration of $\mathrm{AMO}(\mathrm{mg} / \mathrm{L}), \mathrm{C}_{\mathrm{e}}$ is final concentration of AMO (mg/L), $\mathrm{M}$ is mass of adsorbent $(\mathrm{g})$ and $\mathrm{V}$ is volume of solution (L).

\section{RESULTS}

The SEM images give information about the surface morphology. Figure 1. Show the SEM images of MON-NP. According to SEM images, MONNP are stacks of multi-layers with a sheet structure. Regarding to this Figure, these nanoparticles consist of irregular morphology with a size of a few micrometers. Furthermore, the heterogeneous surface of the particles is clear.

Figure 2 shows the amounts of AMO adsorption on MON-NP adsorbent with dosages of $0.1,0.2,0.4,0.6,0.8$ and $1 \mathrm{~g} / \mathrm{L}$. Figure 3 shows that with increasing the adsorbent masses, the adsorption capacities of the adsorbents decreases. So the maximum amount of adsorption with MON-NP occurred when the adsorbent mass was $0.2 \mathrm{~g} / \mathrm{L}$.

The adsorption of AMO on MON-NP was investigated as a function of contact time (10-150 $\mathrm{min})$ at concentrations of $50 \mathrm{mg} / \mathrm{L}$ with an initial solution $\mathrm{pH}$ of 7 . It was noticed that AMO removal increased with time (Figure 3). AMO uptake by MON-NP increased when the initial AMO concentration increased from 10 to $100 \mathrm{mg} / \mathrm{L}$ (Figure 4).

\section{ADSORPTION KINETIC}

The kinetic data of AMO adsorption onto MON-NP was used in MorrisWeber (following Equation) to examine the change in the concentration of sorbate onto sorbent with contact time.

$\mathrm{q}_{\mathrm{t}}=\mathrm{K}_{\mathrm{id}} \mathrm{t}^{1 / 2}+\mathrm{C}$

Where $\mathrm{q}_{\mathrm{t}}$ is the sorbed concentration of AMO at time ' $\mathrm{t}$ '. The MorrisWeber transport $\left(\mathrm{K}_{\mathrm{id}}\right)$ rate constant value is calculated from the slope of the linear plot of Figure $5\left(\mathrm{q}_{\mathrm{t}}\right.$ versus $\left.\mathrm{t}^{1 / 2}\right)$.

In Lagergren, a pseudo-first-order equation was suggested for the sorption of liquid/solid system based on solid capacity. It is assumed in this equation that the rate of change of sorbate uptake with time is proportionate to the difference in the saturation concentration and the amount of solid uptake with time.The Lagergren equation is mostly used in liquid phase sorption. The general equation is given as: ${ }^{23}$

$\log \left(\mathrm{q}_{\mathrm{e}}-\mathrm{q}_{\mathrm{e}}\right)=\log \mathrm{q}_{\mathrm{e}}-\frac{\mathrm{K}_{\mathrm{l}} \mathrm{t}}{2.3}$

Where $\mathrm{q}_{e}$ is the sorbed concentration at equilibrium and $\mathrm{K}_{1}$ is the first order rate constant. The linear plot of $\log \left(\mathrm{q}_{\mathrm{e}}-\mathrm{q}_{\mathrm{t}}\right)$ against time ' $\mathrm{t}$ ' reveals the applicability of the above equation for AMO sorption onto MON-NP. The sorption of AMO onto MON-NP following pseudo-second-order kinetics is expressed as Equation: ${ }^{23}$

$\frac{\mathrm{t}}{\mathrm{q}_{\mathrm{t}}}=\frac{1}{\mathrm{~K}_{2} \mathrm{qe}^{2}}+\frac{\mathrm{t}}{\mathrm{q}_{\mathrm{e}}}$

Where $\mathrm{q}_{\mathrm{t}}$ denotes the amount of AMO adsorbed at time $\mathrm{t}$ and $\mathrm{qe}$ shows that amount at equilibrium $(\mathrm{mg} / \mathrm{g})$. Also, $\mathrm{K}_{2}(\mathrm{~g} / \mathrm{mg} \cdot \mathrm{min})$ is the pseudo-second-order rate constant for the adsorption process. The rate equations and the related values are given in Table 1 . The best-fit model was selected based on the match between experimental $\left(\mathrm{q}_{\mathrm{e} \text { exp }}\right)$ and theoretical $\left(\mathrm{q}_{\text {e cal }}\right)$ uptake values and linear correlation coefficient $\left(R^{2}\right)$ values at four studied concentrations. The values obtained by pseudosecond-order model (Figure 6 and Table 1) were found to be in good agreement with experimental data and can be used to favorably explain the AMO adsorption on MON-NP.

\section{Adsorption isotherms}

To study the adsorption isotherms the experimental data were analyzed using Freundlich, Langmuir and Dubinin-Radushkevich (D-R) isotherm models. The linear forms of Langmuir, Freundlich and D-R can be expressed as follows: ${ }^{24}$

$$
\begin{aligned}
& \frac{\mathrm{Ce}}{\mathrm{q}_{\mathrm{e}}}=\frac{1}{\mathrm{qm}_{\mathrm{m}} \mathrm{K}}+\frac{\mathrm{C}_{\mathrm{e}}}{\mathrm{q}_{\mathrm{m}}} \quad \mathrm{R}_{\mathrm{L}}=\frac{1}{1+\mathrm{KC}_{\mathrm{o}}} \\
& \log q_{\mathrm{e}}=\log K_{\mathrm{F}}+\frac{1}{n} \log C_{\mathrm{e}} \\
& \operatorname{Ln} \mathrm{q}_{\mathrm{e}}=\mathrm{Ln} \mathrm{g}_{\mathrm{m}}-\beta \varepsilon^{2} \quad \quad \mathrm{E}=\frac{1}{\sqrt{2 \beta}}
\end{aligned}
$$

Where $\mathrm{q}_{e}$ is the equilibrium concentration of AMO in the solid phase $(\mathrm{mg} / \mathrm{g}), \mathrm{q}_{\mathrm{m}}$ is the maximum adsorption $(\mathrm{mg} / \mathrm{g}), \mathrm{K}$ is the Langmuir adsorption equilibrium constant $(\mathrm{L} / \mathrm{mg}), \mathrm{K}_{\mathrm{F}}$ is the Freundlich constant representing the adsorption capacity $(\mathrm{mg} / \mathrm{g})(\mathrm{l} / \mathrm{mg})^{\mathrm{n}}$ and $\mathrm{n}$ is the Freundlich constant representing the intensity of adsorption. Also at

\begin{tabular}{|c|c|c|c|c|c|c|c|c|c|c|}
\hline \multirow{2}{*}{$\begin{array}{c}\text { AMO } \\
\text { Concentration } \\
(\mathrm{mg} / \mathrm{L})\end{array}$} & \multirow[t]{2}{*}{$\left(q_{e}\right)_{\exp }$} & \multicolumn{3}{|c|}{$\begin{array}{l}\text { Intraparticle diffusion } \\
\text { model }\end{array}$} & \multicolumn{3}{|c|}{ Pseudo-first order } & \multicolumn{3}{|c|}{ Pseudo-second order } \\
\hline & & $\mathrm{K}_{\mathrm{id}}$ & 1 & $\mathbf{R}^{2}$ & $\left(q_{e}\right)_{\text {cal }}$ & $\mathrm{K}_{1}$ & $\mathbf{R}^{2}$ & $\left(q_{e}\right)_{\text {cal }}$ & $\mathrm{K}_{2}$ & $\mathbf{R}^{2}$ \\
\hline 10 & 9.971 & 0.613 & 3.571 & 0.774 & 4.147 & 0.034 & 0.812 & 9.241 & 0.0072 & 0.999 \\
\hline 25 & 23.49 & 1.623 & 6.114 & 0.814 & 11.92 & 0.051 & 859 & 24.18 & 0.0059 & 0.998 \\
\hline 50 & 45.93 & 3.256 & 8.358 & 0.823 & 23.59 & 0.063 & 0.834 & 39.74 & 0.0047 & 0.998 \\
\hline 100 & 82.72 & 6.045 & 11.82 & 0.805 & 41.68 & 0.067 & 0.861 & 84.36 & 0.0041 & 0.996 \\
\hline
\end{tabular}
$\mathrm{D}-\mathrm{R}$ Eq where $\mathrm{q}_{\mathrm{e}}$ is the amount of AMO adsorbed per unit dosage of the adsorbent $(\mathrm{mg} / \mathrm{g}) ; \mathrm{q}_{\mathrm{m}}$ denotes the monolayer capacity; $\beta$ indicates the

Table 1: The results of kinetic model studies related to the AMO adsorption onto MON-NP.

Table 2: Isotherms constants for the removal AMO onto MON-NP.

\begin{tabular}{ccccccccccc}
\hline \multicolumn{4}{c}{ Langmuir } & \multicolumn{4}{c}{ Freundlich } & \multicolumn{4}{c}{$\mathrm{D}-\mathrm{R}$} \\
\hline $\mathrm{q}_{\mathrm{m}}$ & $\mathrm{R}_{\mathrm{L}}$ & $\mathrm{K}_{\mathrm{L}}$ & $\mathrm{R}^{2}$ & $\mathrm{n}$ & $\mathrm{K}_{\mathrm{F}}$ & $\mathrm{R}^{2}$ & $\mathrm{E}$ & $\mathrm{q}_{\mathrm{m}}$ & $\mathrm{R}^{2}$ \\
\hline 39.41 & 0.041 & 0.144 & 0.998 & 3.47 & 9.451 & 0.847 & 6.476 & 32.47 & 0.925 \\
\hline
\end{tabular}


activity coefficient related to the mean sorption energy and finally $\varepsilon$ is the Polanyi potential.

\section{DISCUSSION}

As can be concluded from the results, due to greater availability of the exchangeable sites or surface area at higher concentrations of the adsorbent, with increasing of adsorbent dosage from $0.2 \mathrm{~g} / \mathrm{L}$ to $1 \mathrm{~g} / \mathrm{L}$, the removal efficiency of AMO increased. This was due to increasing collisions and also free bond on absorbent surfaces. ${ }^{23,25}$

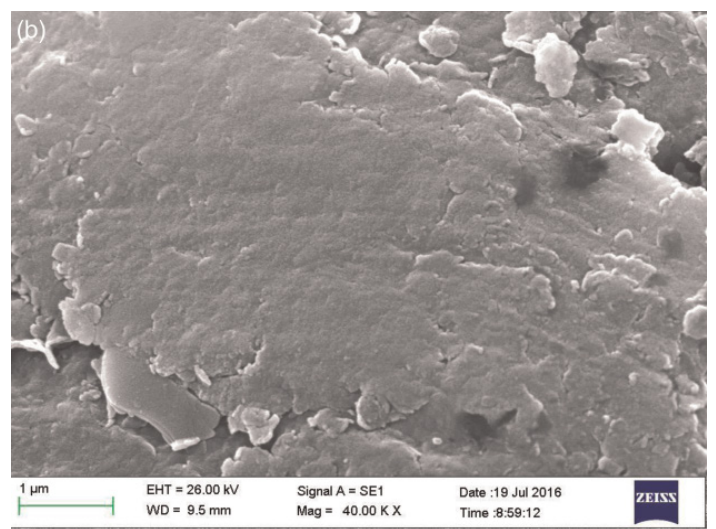

Figure 1: SEM images of montmorillonite nanoparticles.

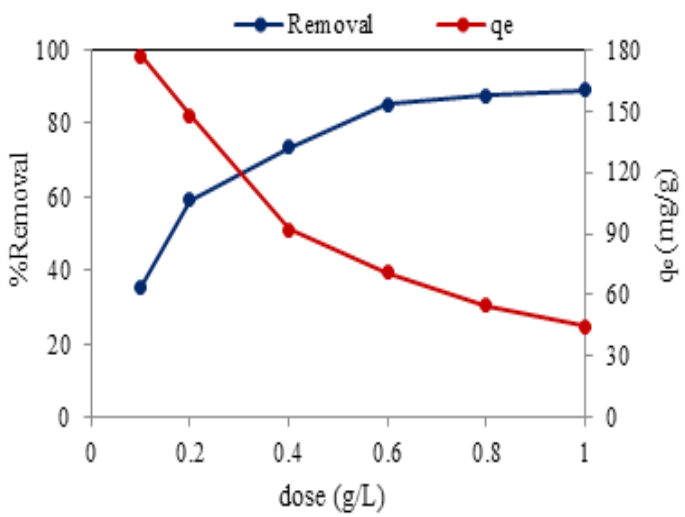

Figure 2: Effect of adsorbent dose on AMO removal efficiency $\left(C_{0}=50 \mathrm{mg} / \mathrm{L}\right.$, $\mathrm{pH}=7$, Contact time $=90 \mathrm{~min}$ ).

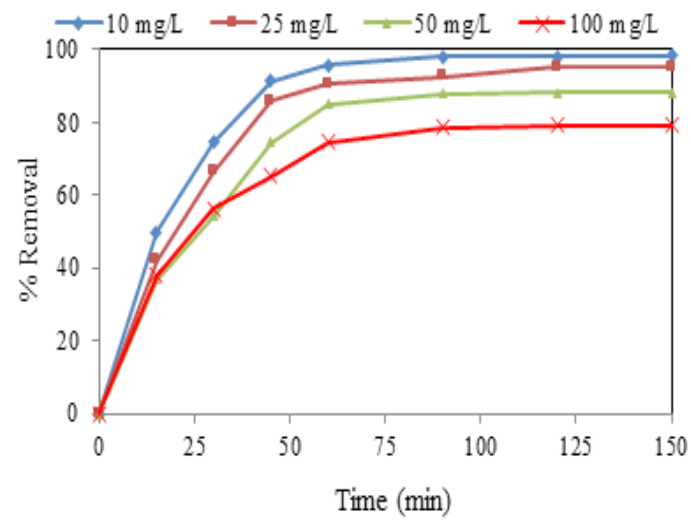

Figure 3: Effect of contact time on AMO removal efficiency ( $\mathrm{pH}=7$ and adsorbent dose $=0.8 \mathrm{~g} / \mathrm{L}$ ).
The trends of the plots in Figure 3 exhibit that AMO uptake was rapid in the beginning followed by a slower removal that gradually reached a plateau. ${ }^{24}$ Maximum removal of AMO was achieved within the first $45 \mathrm{~min}$ of contact time and equilibrium was attained in $90 \mathrm{~min}$. There was no significant change in AMO uptake by MON-NP in the following $150 \mathrm{~min}$. Similar results were observed by Yu who investigated the effect of contact time on removal of tetracycline from aqueous solution by carbon materials and indicated that adsorption increases with increasing contact time. ${ }^{3}$

The effect of initial AMO concentration on equilibrium adsorption was also investigated at five different initial AMO concentrations

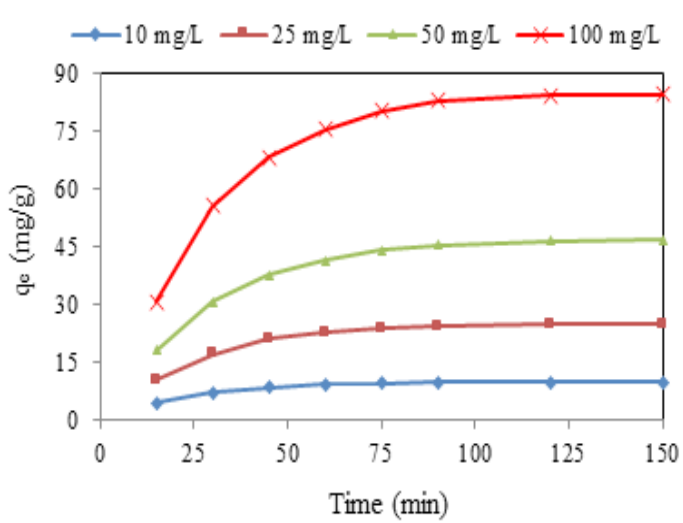

Figure 4: The effect of initial concentration on the adsorption capacity $(\mathrm{pH}=7$ and adsorbent. dose $=2.5 \mathrm{~g} / \mathrm{L}$ ).

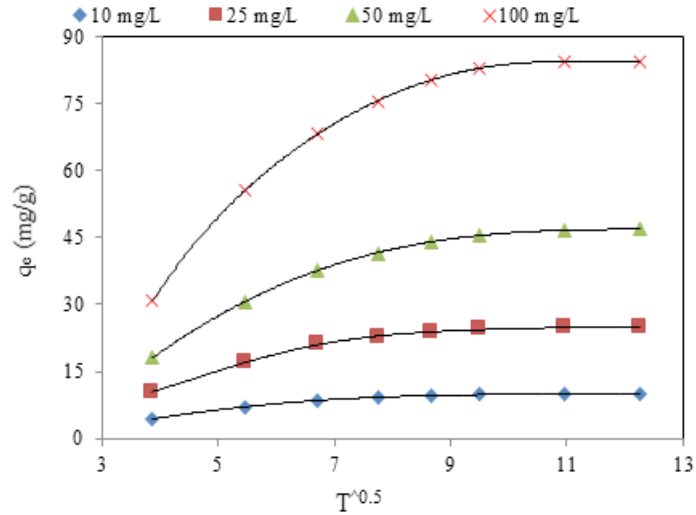

Figure 5: Intra-particle diffusion plots for of AMO adsorption onto MON-NP.

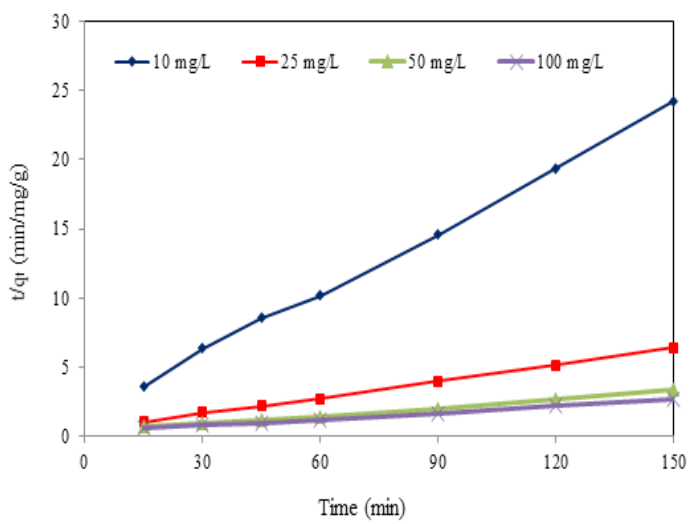

Figure 6: Pseudo-second order kinetics of AMO adsorption onto MON-NP. 
Balarak, et al: Removal of Amoxicillin by Montmorillonite

(10-100 mg/L). AMO uptake by MON-NP increased when the initial AMO concentration increased from 10 to $100 \mathrm{mg} / \mathrm{L}$ (Figure 5). This behaviour can be explained due to the increase in the driving force of the concentration gradient, as an increase in the initial AMO concentration. ${ }^{26}$ Such phenomenon is common in a batch reactor with either constant adsorbent dose or varying initial adsorbate concentration or vice versa. $^{22,27}$

Most of adsorption processes in various solid phases depend on the time element. Knowledge of the kinetics of these processes is important to understand the dynamic interactions of AMO with MON-NP and predict the rate of adsorption with time. Some kinetic models, i.e Morris- Weber, Lagergren and pseudo second order models were used for their validity with the experimental adsorption data for the adsorption of AMO onto MON-NP. These models were supposed to offer no mass transfer (both external and internal) resistance to the overall adsorption process. ${ }^{28} \mathrm{~A}$ study was conducted on the adsorption kinetics and the findings suggest that these rates along with the solute uptake rate control the residence time of adsorbate uptake at the solid-solution interface including the diffusion process. ${ }^{29,30}$

The intra-particle diffusion approach can be used to predictif intraparticle diffusion is the rate-limiting step. The data exhibitmulti-linear plots, revealing that the process is governed by two ormore steps (Figure 6). The first linear portion (phase 1) at both concentrations, can be attributed to the immediate utilization of the most readily available sorbing sites on the sorbent surface. Phase 2 may be attributed to very slow diffusion of the sorbate from thesurface site into the inner pores. Thus initial portion of AMO sorptionby MON-NP may be governed by the initial intra-particle transport of AMO controlled by surface diffusion process and the later part controlled by pore diffusion. ${ }^{31}$

Table 2 presents the statistical results together with the isotherm constants. Results suggest that the AMO adsorption by MON-NP can bematched using the Langmuir equation. Also, the D-Requation suggests there is a considerable correlation factor. It can be understood from the $\mathrm{D}-\mathrm{R}$ isotherm that the heterogeneity of energies is close to the adsorbentsurface. The quantity is related to the mean sorption energy, E, which is the free energy for the transfer of 1mole of AMO from the infinity to the surface of the adsorbent. ${ }^{27}$ It is clear that we can use the $\mathrm{E}$ magnitude to estimate the adsorption type. If this value goes below $8 \mathrm{~kJ} / \mathrm{mol}$, the adsorption type is expressed by the physical adsorption and between 8 and $16 \mathrm{~kJ} / \mathrm{mol}$ the adsorption type can be explained by ion exchange. ${ }^{28}$ In this study, the E values were below $8 \mathrm{~kJ} / \mathrm{mol}$. This reveals that the adsorption of AMO onto MON-NP was in fact a physical adsorption.

\section{CONCLUSION}

The present study was conducted to evaluate the feasibility of MON-NP for AMO removal from aqueous solutions. Batch adsorption studies were performed as a function of contact time, initial AMO concentration and adsorbent dose and influence of other interfering anions. AMO sorption kinetics was well fitted by pseudo-second-order kinetic model. The maximum sorption capacity of MON-NP for AMO removal was found to be 39.41 at $25 \pm 2^{\circ} \mathrm{C}$. The AMO sorption has been well explained using Langmuir isotherm model. Results from this study demonstrated the potential utility of MON-NP for AMO removal from water.

\section{ACKNOWLEDGEMENT}

The authors are grateful from Student research committee of Zahedan University of Medical Sciences because of supporting of this research.

\section{CONFLICT OF INTEREST}

The authors declare no conflict of interest.

\section{ABBREVIATIONS}

MON-NP: Montmorillonite Nanoparticles; AMO: Ciprofloxacin.

\section{REFERENCES}

1. Liu Z, Xie H, Zhang J, Zhang C. Sorption removal of cephalexin by $\mathrm{HNO}_{3}$ and $\mathrm{H}_{2} \mathrm{O}_{2}$ oxidized activated carbons. Sci China Chem. 2012;55(9):1959-67.

2. Liu H, Liu W, Zhang J, Zhang C, Ren L, Li Y. Removal of cephalexin from aqueous solution by original and $\mathrm{Cu}$ (II)/Fe (III) impregnated activated carbons developed from lotus stalks kinetics and equilibrium studies. J Hazard Mater. 2011;185(2-3):1528-35.

3. Yu F, LiY, Han S, Jie Ma J. Adsorptive removal of antibiotics from aqueous solution using carbon Materials. Chemosphere. 2016;153:365-85.

4. Zhang L, Song X, Liu X, Yang L, Pan F. Studies on the removal of tetracycline by multi-walled carbon nanotubes. Chem Eng J. 2011;178:26-33.

5. Azarpira H, Mahdavi $Y$, Khaleghi O. Thermodynamic Studies on the Removal of Metronidazole Antibiotic by Multi-Walled Carbon Nanotubes. Pharm Lett. 2016;8(11):107-3.

6. Balarak D, Mostafapour FK, Bazrafshan E, SalehTA. Studies on the adsorption of amoxicillin on multi-wall carbon nanotubes. Water Sci Technol. 2017:75(7):1599606.

7. Choi KJ, Kim SG, Kim SH. Removal of antibiotics by coagulation and granular activated carbon filtration. J Hazard Mater. 2008;151(1):38-43.

8. Zhang W, He G, Gao P, Chen G. Development and characterization of composite nanofiltration membranes and their application in concentration of antibiotics. Sep Purif Technol. 2003;30(1):27-35.

9. Ahmadi S, Banach A, Mostafapour FK. Study survey of cupric oxide nanoparticles in removal efficiency of ciprofloxacin antibiotic from aqueous solution: Adsorption isotherm study. Water Sci Technol. 2017;89:297-303.

10. Balarak D, Mostafapour FK. Photocatalytic degradation of amoxicillin using UV/Synthesized $\mathrm{NiO}$ from pharmaceutical wastewater. Indones $\mathrm{J}$ Chem. 2019;19(1):211-8.

11. Gao J, Pedersen JA. Adsorption of Sulfonamide Antimicrobial Agents to Clay Minerals. Environ Sci Technol. 2005;39(24):9509-16.

12. Peterson JW, Petrasky LJ, Seymourc MD, Burkharta RS, Schuilinga AB. Adsorption and breakdown of penicillin antibiotic in the presence of titanium oxide nanoparticles in water. Chemosphere. 2012;87(8):911-7.

13. Ghauch A, Tuqan A, Abou AH. Antibiotic removal from water: Elimination of amoxicillin and ampicillin by microscale and nanoscale iron particles. Environ Pollut. 2009;157(5):1626-35

14. Tavassoli P, Bazrafshan E, Mostafapour FK, Maghsoodi Z. Efficiency of UV Activated Persulfate in Removal of Ofloxacin from Aqueous Solutions. J Mazandaran Univ Med Sci. 2018;28(159):116-29.

15. Ji L, Chen W, Duan L, Zhu D. Mechanisms for strong adsorption of tetracycline to carbon nanotubes: A comparative study using activated carbon and graphite as adsorbents. Environ SciTechnol. 2009:43(7):2322-7.

16. Alexy R, KumpelT, Kummerer K. Assessment of degradation of 18 antibiotics in the closed bottle test. Chemosphere. 2004;57(6):505-12

17. Yue QY, Li Q, Gao BY, Yuan AJ, Wang Y. Formation and characteristics cationic-polymer/ bentonite complexes of as adsorbents for dyes. Appl Clay Sci. 2007;35(3-4):268-75.

18. Rytwo G, Huterer-Harari R, Dultz S, Gonen Y. Adsorption of fast green and erythrosin-B to montmorillonite modified with crystal violet. JTherm Anal Calor 2006;84(1):225-31.

19. Balarak D, Azarpira H. Rice husk as a Biosorbent for Antibiotic Metronidazole Removal: Isotherm Studies and Model validation. Int J ChemTech Res. 2016;9(7):566-73.

20. Carabineiro A, Thavorn-Amornsri T, Pereira F, Figueiredo L. Adsorption of ciprofloxacin on surface modified carbon materials. Water Res. 2011;45(15):4583-91.

21. Hu D, Wang L. Adsorption of amoxicillin onto quaternized cellulose from flax noil: Kinetic, equilibrium and thermodynamic study. J Taiwan Inst Chem Eng. 2016;64:227-34.

22. Gao Y, Li Y, Zhang L, Huang H, Hu J, Shah SM, et al. Adsorption and removal of tetracycline antibiotics from aqueous solution by graphene oxide. J Colloid Interface Sci. 2012;368(1):540-6.

23. Kerkez-Kuyumcu Ö, Bayazit SS, Salam MA. Antibiotic amoxicillin removal from aqueous solution using magnetically modified graphene nanoplatelets. J Ind Eng Chem. 2016;35:225-34.

24. Ghauch A, Tuqan A, Assi HA. Elimination of amoxicillin and ampicillin by micro scale and nano scale iron particles. Environ Pollut. 2009;157:1626-35. 
25. Kim SH, Shon HK, Ngo HH. Adsorption characteristics of antibiotics trimethoprim on powdered and granular activated carbon. J Ind Eng Chem. 2010;16(3):344-9.

26. Adrianoa WS, Veredasb V, Santanab CC, Gonçalves LRB. Adsorption of amoxicillin on chitosan beads: Kinetics, equilibrium and validation of finite bath models. Chem Eng J. 2005;27(2):132-7.

27. Gao Y, Li Y, Zhang L, Huang H, Hu J, Shah SM, et al. Adsorption and removal of tetracycline antibiotics from aqueous solution by graphene oxide. J Colloid Interface Sci. 2012;368(1):540-6.

28. Ghauch A, Tuqan A, Assi HA. Elimination of amoxicillin and ampicillin by micro scale and nano scale iron particles. Environ Pollut. 2009;157:1626-35.

29. Senthilkumaar S, Varadarajan PR, Porkodi K, Subbhuraam CV. Adsorption of methylene blue onto jute fiber carbon: Kinetics and equilibrium studies. J Colloid Interface Sci. 2005;284(1):78-82.

30. Aksu Z, Tunc O. Application of biosorption for Penicillin G removal: Comparison with activated carbon. Process Biochemistry. 2005;40(2):831-47.

31. Guler UA, Sarioglu M. Removal of tetracycline from wastewater using pumice stone: Equilibrium, kinetic and thermodynamic studies. J Environ Health Sci Eng. 2014;12(1):79-87.

Article History: Submission Date : 20-02-2020; Revised Date : 01-03-2020; Acceptance Date : 14-04-2020.

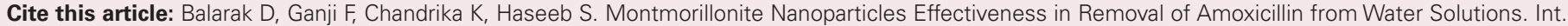
J. Pharm. Investigation. 2020;10(2):122-6. 